\title{
Prostate Acinar Adenocarcinoma, Foamy Gland Variant
}

National Cancer Institute

\section{Source}

National Cancer Institute. Prostate Acinar Adenocarcinoma, Foamy Gland Variant. NCI

Thesaurus. Code C39882.

A variant of acinar prostate adenocarcinoma characterized by the presence of malignant cells with abundant xanthomatous appearing cytoplasm. 